\title{
FUNDAVIDA: A HOLISTIC CURRICULUM EVALUATION OF A NON-PROFIT ENGLISH LANGUAGE PROGRAM
}

\begin{abstract}
The following document is a curriculum evaluation of an English education program, Syde by Syde, for at-risk youths and their mothers in nonprofit institution, FundaVida, in three urban communities in the South of San Jose, Costa Rica. The evaluation is based on Stufflebeam's Context, Input, Process, Product Model of curriculum evaluation. It provides the organization with a formal written document for potential donors, volunteers, students, and other interested parties about the organization's activities, methodologies, achievements and continuing needs as well as recommendations for future development of the bilingual English education program of FundaVida.
\end{abstract}

Key words: program evaluation, English as a foreign language, at-risk youth.

\section{Introduction}

This project stems from a desire to offer a free curriculum evaluation to a non-profit organization, FundaVida, which provides meaningful services to youth and mothers in three at-risk communities in the South of San José: 25 de Julio de Hatillo, Linda Vista de Patarrá, y Concepción de Alajuelita. As such, this evaluation provides the organization with a formal written document for potential donors, volunteers, students, and other interested parties about the organization's activities, methodologies, achievements and continuing needs as well as recommendations for future development of the bilingual English education program of FundaVida. While the program offers other services, the goal of this curriculum evaluation is to assess the materials, methodologies, goals, and outcomes of Bilingual English education program, Syde by Syde, to see where the program is achieving well and where it could continue to grow to meet the population's English language needs. The evaluation is based on Stufflebeam's Context, Input, Process, Product Model, also known as CIPP, which "considers evaluation to be a continuing process. In the CIPP model, the assumptions are 1) that evaluations have a vital role in stimulating and planning change and 2) that evaluation is an integral component of an institution's regular program" (Tunc, 2010).

\section{Context Evaluation}

\section{Audience and Goals}

This evaluation will benefit students in the program, the communities where the courses are offered, the director and staff in the program, donors and volunteers, and Costa Rican society

${ }^{1}$ mbradleyesp@gmail.com 
as a whole since education provides these students with the tools to resist drugs and crime and contribute in productive ways to the betterment of the Costa Rican community.

\section{Context Inventory}

FundaVida offers educational support, bilingual education programs, computer labs, children's and teen clubs, and counseling for three at-risk communities in the South of San José that do not receive the resources they need in order to thrive and provide opportunities for their youngest members. The program began in 1996 in Concepción de Alajuelita, then expanded to 25 de Julio in Hatillo in 2000, and finally to Linda Vista de Patarrá in 2005. Through FundaVida's interactive and supportive methodology, the students in the programs offered at the institution have job opportunities starting from high school and many go on to be the first to graduate high school let alone attend university. The program provides special attention to address the students' unique needs and adapt to their learning styles. By getting the mothers involved with their own and their children's education, it offers them hope and provides them with the skills to help their children achieve their dreams: dreams that before attending FundaVida, they could not even verbalize; furthermore, it allows the women to dream bigger for themselves.

\section{Needs of the Community}

According to the video Como Amanecera by FundaVida, the south of San Jose suffers from drug use and trafficking, domestic and street violence, and prostitution and sex trafficking, and high school drop-out rates. In fact, currently in Costa Rica, 92\% of children under eighteen in marginal communities are consuming drugs at least once a month, one-fourth of students are dropping out of school by seventh grade, fifty percent do not graduate high school, and the homicide rate has doubled in the last 15 years (FundaVidaCR, 2012). Furthermore, due to other problems in the community and the popularity of Costa Rica as a place for sexual tourism (of which $80 \%$ of sexual tourists are from the United States), many girls are put into prostitution before they are twelve years old. Furthermore, sexual abuse is rampant in the communities (ibid). Thus, the needs for this community are clear in terms of educational support, drug education, job opportunities, counseling, role-models, and networking of different organizations. However, the most essential need is hope: hope for a better future with new possibilities in order to stop these cycles of violence and poverty.

\section{Vision/Mission/Values}

Vision. To break the destructive cycle of poverty by offering hope to at-risk youth in communities with problems (FundaVida, 2020).

Mission. To empower the youth to overcome problems such as dropping out of high school, violence and poverty through programs that have a proven impact (ibid).

Values. Hope, purpose, and freedom (ibid).

\section{Case Studies of Youth Impacted}

While perhaps not measurable by numbers, at least twelve youths are highlighted on the organization's website discussing how this organization has changed their lives in terms of forgiveness, motivation, and hope for the future. One of such examples is Kimberly, who is from Linda Vista. Kimberly was in charge of her three younger siblings at just 10 years of age after being abandoned by her father, yet through the support of FundaVida, Kimberly is now a role model in her community and has graduated high school, is working on her English skills at the Centro Cultural, has a job as a legal assistant in a law firm and has just finished her first semester at the UNED (ibid). 


\section{English Program Results}

According to the programs annual report in 2015, the program had 12 students in level 8 of the Program of "English Now" in the Centro Cultural Costarricense Norteamericano, 86 active students in the internal program "Syde by Syde", 76 students who received certifications from Dulingo and they held a workshop about studying and learning techniques. In the organization's financial plan, $15 \%$ of the budget goes towards supporting Bilingual English Education (ibid).

\section{Staff Profile}

The organization as a whole has 11 paid staff as well as student and mother volunteers. Rebeca Mayorga is the current English coordinator of the program and she also has hired several teachers who have completed the program and now assist in leading the classes. These teachers are often young and from the community so while they have little experience, they know the population well and are highly motivated to help others like themselves.

\section{Funding}

The organization is maintained and funded through private donations from organizations such as Amazon, EPA, Cetransa and others.

\section{Instructional Material and Resources}

The internal English program "Syde by Syde" is equipped with computers and laboratories, tablets, and other technological devices but internet access can be a major limitation as internet companies often do not provide adequate services in these neighborhoods. In the English classroom, they do not use specific textbooks, but rather use the whiteboard board and other printed and constructed materials and rely on the creativity and expertise of the professors.

\section{Context Conclusion}

FundaVida, is an organization that makes a huge impact in its community through grassroots organizing and fundraising. The problems they face are due to the problems in the community themselves, such as violence, poverty, hunger, sexism, and drop-out rates as well as having few staff and lack of resources such as textbooks and internet connection. Nevertheless, despite the limitations, through the motivation of the staff and the support of private donors and volunteers, the program continues to grow in order to provide the resources needed to help the at-risk youth.

\section{Input Review}

In order to give a full analysis, the input review discusses some language acquisition theories with children/adolescent learners as well as the particularities and challenges of learning a foreign language in at-risk youth communities. In general, "input evaluators assess the school's capabilities to carry out the task of evaluation; they consider the strategies suggested for achieving program goals and they identify the means by which a selected strategy will be implemented" (Tunc, 2010, p. 24). Thus, the section also looks at the strategies the program uses in order to assist in foreign language acquisition, which, in this case, is constructivism employed through the use of stations and small group work and a backwards design approach. Furthermore, an input review asks the following questions:

Are the objectives stated appropriately? Are the objectives congruent with the goals of the school? Is the content congruent with the goals and objectives of the program? Are 
the instructional strategies appropriate? Do strategies exist that can also help meet the objectives? What is the basis for believing that using this content and these instructional strategies will enable educators to successfully attain their objectives? (Tunc, 2010, p. 26).

After reviewing foreign language theory based on the population, the section addresses how well the institution integrates its teaching methodology in order to attain its goals and objectives or what impedes this process.

One of the most prominent theorists in in language acquisition, Noam Chomsky, proposed that humans had a natural propensity for language acquisition known as LAD or Language Acquisition Device based on his observations that young children are able to pick up language naturally and without much effort and without sufficient input. He believed that LAD was "a sort of neurological wiring that, regardless of the language to be acquired, allows a child to listen to a language, decipher the rules of that language, and begin creating with the language at a very young age" (Escamilla and Grassi, 2000, p. 3-4). Chomsky is the forefront thinker in the nativist language acquisition theory, which "explores the linguistic aspects of language acquisition and provides an answer to the question of how people acquire a second language" (ibid). While Chomsky wrote about children and first language acquisition theory, Krashen expanded and applied this theory to how learners acquire a second language through his Monitor Theory and the Input Hypothesis. Krashen believes that second language learners need sufficient and understandable input in order to process this information and language in the LAD. He joins nativist theory with the communicative approach suggesting that "providing students with meaningful comprehensible input that contains grammar, but focuses on communication, will enable students to naturally acquire the necessary grammar" (ibid). He posits two systems in his Learning/Acquisition Hypothesis; according to Krashen, we first obtain "the acquisition system," which happens when we receive comprehensible input with a focus on communication and use of the language, and later "the learning system" when we gain conscious understanding of the language and know the rules. "Krashen believes that in order to fully use language in a communicative setting, the second language student must first acquire the language before learning is introduced" (ibid). While in second language acquisition, this may be completely true when immersed, in a foreign language setting with limited exposure to the language, students may begin to learn and acquire at the same time by having meaningful experiences in the language, clear explanations, receiving comprehensible input, and practicing with expressive exercises. This is why at FundaVida, while the program does emphasize communication through comprehensible input, it also focusses on teaching and having students produce and practice with experiences and working with the facilitators and other learners.

Perhaps even more important in the context of the students acquiring a $2^{\text {nd }}$ language in FundaVida, Krashen also developed the Affective Filter Hypothesis. In the Affective Filter Hypothesis, he posits that learners sometimes have mental blocks that impede them from acquiring a $2^{\text {nd }}$ language such as "emotional variables that can prevent learning" (Escamilla and Grassi, 2000, p. 9). As students who have been told by society, the school system, and even their families that they cannot learn and do not have worth, it is crucial that educators and the staff at FundaVida help increase their confidence and self-esteem so that they can effectively acquire the skills they need. Krashen asserts that "the affective filter can be prompted by many different variables including anxiety, self-confidence, motivation and stress" (Escamilla and Grassi, 2000, p. 11). By helping to remove these emotional barriers, the 
input they are receiving can actually reach the brain and activate the learning and acquisition systems. Likewise, environmentalists, another branch of language acquisition theory, focus on the outside learning environment that has an effect on student's acquisition of a 2nd language. For instance, Schumann, the most renown environmental theorist, created the "Acculturation Model" that elucidates how a learner's relationship with the target language, such as the social and psychological distance, determines a learner's ability to acquire a language. He contributed the idea of social distance which relates to how close the two cultures are between the learner's native culture and the target language culture. As Escamilla and Grassi (2000) explain, "Schumann hypothesizes that the greater number of negative social factors affecting a second language learner's (SLL) relationship with the target language $(T L)$ group, the more difficult it will be for the second language learner to acquire the target language" (p. 11). Some of these negative social factors include feeling subordinate to the target culture and being enclosed (only in contact with members of their own community). Thus, while teaching English to FundaVida students, educators must also consider how to teach cultural aspects of the language in non-hierarchical ways as well as help the students have contact with native speakers or other English speakers when at all possible. Likewise, students need to view becoming proficient in English as desirable, possible, and necessary in order to have the motivation to continue.

As we have seen by analyzing cognitive theories, students in at-risk communities, who live with poverty, violence, drugs, family problems, prostitution and lack of resources, need extra attention from mentors and caregivers. These learners are often lacking these fundamental parts of childhood and cognitive development in overcrowded public schools, in harsh community settings and families that do not have the means to support them emotionally and physically. As such, it is not just the English classes alone that must be evaluated. The program needs to be assessed in a holistic manner because the acquisition of the foreign language is just one of the goals and cannot be seen in isolation. We have to understand the students individual educational, emotional and environmental needs. For instance, as the article on Serving At-Risk Youth states, "Services directed at social/emotional needs are also necessary. Involving youth in social skills groups or outside activities helps to engage them in the school process and redirect their energies toward positive alternatives" (2020). Obviously, the main objective of the English program is to help them acquire the language, but it must do this in a way that is beneficial to the whole student, improving self-esteem, life skills, and keeping them in school by offering hope for a future they might not have imagined for themselves.

In order to do this, FundaVida uses objectives aimed at at-risk youth like structured learning environments: "structured learning environments, with smaller than usual teacher to student ratios, are conducive to re-engagement. Students typically benefit from a focus on the core academic skills (reading, writing, and math). Tutoring services and computer programs can also be used to engage youth and help further academic skills" (Serving at-risk youth, 2020). Likewise having the parents involved (or the mothers in this case) is fundamental to connect their home life to their learning objectives. The mothers may also not have had negative experiences with traditional school systems, so showing them the value of education will help instill that value in their children. "The connection between home and school is an important factor. When families feel disaffected by the school system, they need help to be able to reengage in the schooling of their child. Schools should encourage parents to be involved with their children's school life" (ibid). In addition to the families and parents getting involved, which is not always possible, the facilitators themselves need to establish a personal relationship with the students: relationships that are discouraged in traditional educational 
settings. Then the facilitators can help learners in their personal and educational growth in realistic ways. "Students won't confer trust to an adult based on his or her role as a counselor, psychologist, or social worker. We have to earn it by building a relationship.... From the base of a caring relationship, we can help students form realistic and reachable career, personal, and educational goals" (Elias, 2009). Community and after/before school programs like the one in FundaVida not only teach a language, they also help students thrive in environments that have damaged them in so many ways. It helps build them up again, give them direction and a safe place to grow and learn in a supported, loving environment with their community members surrounding them They learn they are not alone and as a community they can strive for a different life:

The feeling of being engaged in a setting or group happens when students have opportunities to receive positive recognition and to make positive contributions, can spend time in environments in which teamwork is encouraged, and get help learning new skills that they find valuable and helpful in their lives. Engaging settings in the school and the community have logos, mottos, missions, and other tangible things that allow students to experience a sense of belonging and pride (ibid).

FundaVida does this through its methodology, through its connection with counselors and personal tutors, and from the positive reputation it has in each of its three communities. Furthermore, it uses a backwards design approach which puts students learning objectives first to make realistic and useful contributions. As Ed Forrest affirms, "the Backward Design framework puts student learning outcomes at the center, and offers teachers the flexibility to structure both the learning experience and the evaluative tools used to gauge students' progress, so that they align appropriately with the course content, and so that they foster desirable learning outcomes" (2017). Thus, as is customary with backwards design, FundaVida analyzes what learners "need to be familiar with", what they "need to know" and what "enduring understandings" will they take with them after the course.

\section{Process}

The next section of the paper applies the process section of the evaluation. In the process part of the CIPP evaluation, "the main purpose is to provide feedback about needed modification if the implementation is inadequate. That is, are program activities on schedule? Are they being implemented as planned? Are available resources being used efficiently? And do program participants accept and carry out their roles?" (Tunc, 2010, p. 29). Hence, this section of the evaluation contains qualitative data collection strategies including classroom observations and participant observations in order to understand the program from the inside. After the original structured interviews (see Appendix A), I chose this evaluation method in conversation with the English director because of the sensitivity of a high-risk community. As Kawulich explains, "In recent years, the field of education has seen an increase in the number of qualitative studies that include participant observation as a way to collect information. Qualitative methods of data collection, such as interviewing, observation, and document analysis, have been included under the umbrella term of "ethnographic methods" in recent years" (2005, p 4). All of these "ethnographic methods" are used in the different steps of this CIPP program evaluation model because the students and teachers in the program are more willing to talk with me honestly if I am not an outside evaluator but also a volunteer in the community. In these communities because of problems previously stated, 
they can be weary of outsiders coming in and judging them but are more open to people there to help. Thus, I decided not to complete surveys as they are unlikely to give me accurate information, as participants may fear repercussions against the program that they cherish and we have different degrees of literacy in the community. Kawulich describes some of the benefits of participant observation as a data collection method (2005, p. 4):

They provide researchers with ways to check for nonverbal expression of feelings, determine who interacts with whom, grasp how participants communicate with each other, and check for how much time is spent on various activities. Participant observation allows researchers to check definitions of terms that participants use in interviews, observe events that informants may be unable or unwilling to share when doing so would be impolitic, impolite, or insensitive, and observe situations informants have described in interviews, thereby making them aware of distortions or inaccuracies in description provided by those informants.

Hence, I spoke casually with the students, volunteers, and workers, conducted two formal interviews (Appendix A), completed two classroom observations (see Appendix B), one of which I worked as a volunteer, and taught a class myself with guidance from the director and help from the moms and other volunteers in order to complete this evaluation and get an inside perspective of the methodologies used and the learning needs and accomplishments.

\section{Class Observation 1: Age 13-17, Advanced level, 12 Students}

Description. The students worked individually but were able to speak with their classmates to ask for guidance to complete twelve grammatical challenges on the board reviewing the material they had seen in the level.

Strengths. The professor encouraged active student participation by making challenging grammatical tasks on the board in which students had to complete individually giving useful feedback and support as the students completed each task. The students had a great rapport with each other and the professor and were engaged and challenged by the tasks. Only English was used throughout the lesson. Corrections were given in an encouraging manner to foster motivation and correct errors in a friendly manner.

Suggestions for improvement. The task was very grammatically based and somewhat out of context. While it did require communication and advanced cognitive skills, the lesson did not integrate reading or listening other than the instructions. Even though technology is a limitation, some effort could be put into finding alternative ways to bring in video and audio, concentrate on group work, and have a better integration of the skills.

\section{Class Observation 2: Age 11-15, Beginner level, 17 students}

Description. Each student needed to complete seven tasks based on what they had seen in the course. It focused on oral production. The advanced students from the other group facilitated the lesson, corrected and verified the tasks but a teacher created the plan and wrote the instructions on the whiteboard. (See Appendix C)

Strengths. This group was very similar to the last lesson. Each student was accountable for finishing each task by producing questions, reading numbers, spelling and making positive and 
negative statements about themselves and their family members. It was a great way to conclude their course and practice what they had learned throughout. Each of the 17 students was engaged in his/her tasks and received immediate feedback.

Suggestions for improvement. Similar to the last group, some of the tasks were a little out of context. They needed to read the numbers on the board and spell the words, but there was no context as to why. Also, no listening or reading tasks were utilized and only some students wrote their answers before checking the task. It was not clear if it was required to be written and spoken or just spoken. There needs to be more integration of the skills.

\section{Participant Based Observational Analysis}

Selected Group. As a way to fully understand the project and the population as well as to help out the institution as much as possible, I have decided to conduct research while also participating as an instructor in the course. By doing ethnographic research of this type, I can acquire a better understanding of the population and their unique needs and what resources are available in the program. As I had already observed an advanced and beginner level course of adolescents, I chose to work with a group of first graders to see how this population differs from the ones previously observed. For my class presentation, I worked with a group of 18 students from 8:30 to 10:30 on a Tuesday morning the particular students I worked in this project had a much lower level since they are a younger population in the first level of the program. They are true beginners but are also used to receiving instructions in English. For this particular group of children, it is the class before they graduate from the level, and, as such, it is a great opportunity to use creative methodologies in order to review everything seen at the level. Furthermore, the director of the program personally said she could use help with this group since she did not have a class planned and is very busy with administrative aspects of program such as planning their graduation party for the following week, which really helps motivate the students to continue. With this group, I was able to support the program by assisting in a need they have while also assessing how the program handles 18 first graders for a 2-hour English class. I worked in coordination with the English director to try to apply the methodologies of the program and see how the mothers and the learners respond and handle the learning tasks.

Classroom needs and plan. The students need to have constant supervision and be actively engaged during the two-hour lesson. Some of the students have minor behavioral problems such as hyperactivity and need help staying focused and to switch activities often. The students are at the end of the young learners' beginner level and need to practice reading, writing, listening and speaking skills around four main topics: the alphabet, numbers, colors and very simple questions and answers. There are various volunteers (three mothers and one advanced-teenage teacher) who are there to help me run the class and assist with the students. Since this is a large group of diverse young learners, the mothers, a teacher/learner volunteer and I worked in four different stations with the children. Each station developed a different topic: Station 1: Colors, Station 2: Questions, Station 3: Colors, and Station 4: The Alphabet. The class began in a circle with the whole group and sing songs and play a game and then we divide the group into 4 smaller groups which rotated from station to station. Finally, the class closed with a goodbye song and lead the students in a line for their caregivers to receive them. The different stations had interactive materials using constructivist methodology that include different learner styles such as audio-visual and kinesthetic: the students played with food coloring in water, had interactive questions in the shape of fish, 
painted, sang songs, and used puzzles to mention a few. Furthermore, each adult had no more than five students at a time to help address individual needs.

Strategies to work with the chosen population. The strategy chosen to work with this specific population was stations. They students were divided in four groups as there are four stations. After achieving the objective in each station and the given time concludes, the students rotate until all four groups conclude each station.

Learning Objective. Before starting the project, I discussed with English director which topics the children saw throughout the course. Therefore, my objective was to make a lesson in which the students could reinforce and review topics that the students already had experience with: the numbers 1-15, the alphabet, simple questions and answers, and colors.

\section{Reflection}

Overall, the project was a great success and the students saw all of the learning tasks in a productive and engaging way. The students were very motivated and excited and participated in each of the activities developed. It was a lovely closing class to their course before they moved to the last level to review the topics and have fun at the same time. Through the lesson, the following objectives were achieved through the use of constructivist methodology and small group workstations:

- Engage each student in interactive small group work in four stations

- Encourage cooperative learning

- Reinforce skills acquired throughout the course

- Check verbal and visual recognition of letters of the alphabet

- Introduce phonetic elements of the alphabet

- Practice verbal and visual recognition of colors

- Encourage exploration of color combinations with primary and secondary colors

- Verbalize opinions about their favorite colors

- Practice verbal and visual recognition of numbers

- Apply mathematical concepts with opinions through yes/no questions

- Role-play simple conversations about personal information

- Check pronunciation and understanding of vocabulary acquired in the course

- Engage with peers and facilitators in a friendly supportive manner

- Participate in warm-up and good-bye activities

As mentioned previously, the program uses a constructivist approach as constructivism goes against the behaviorist methodology used in traditional classrooms that often leaves the children disconnected from their learning processes. Even through the MEP has changed its English program to use constructivism in theory, in many public schools, the teachers do not have the training to implement it well and the students' experiences with English are limited to memorization and repetition. In contrast, in constructivism "the central principles of this approach are that learners can only make sense of new situations in terms of their existing understanding. Learning involves an active process in which learners construct meaning by linking new ideas with their existing knowledge" (Naylor \& Keogh, 1999, p.93). Thus, in the class, since volunteers help, they often use small groups like I did in this lesson, so the students have personalized experiences and conduct experiments in English. 
Furthermore, at risk-youth particularly need to be actively engaged since they are often deprived of the individual attention they deserve which can lead to behavioral problems as they seek this attention. However, the use of small groups mitigates this concern for more productive learning in each individual student: "Teaching in small groups allows you to individualize instruction, provide meaningful and prompt feedback, and better evaluate student progress ... With a small group (four to six students is ideal), students learn more effectively than in large groups, and you have the opportunity to use more hands-on learning as well as give immediate feedback" (Sayed, 2011). In addition, by having the students move from one station to the next, students that have trouble paying attention for longer periods of time (a consideration for any group of $1^{\text {st }}$ graders) get more individualized attention. In the course I tried to follow Abou-Sayed's (2011) advice: "The workstation assignment or activity needs to be engaging, self-correcting, and meaningful. Be sure to provide clear, concise, and developmentally appropriate instructions for each activity."

Despite the effectiveness of the small groups work stations and the materials developed, I did find some ways in which I could improve. However, since the program uses this methodology more often, they are better equipped to make smooth transitions. One weakness I had was the use of transitions between topics. As Sayed (2011) explains:

To ensure a smooth transition between workstations and to and from small groups, it is crucial to have a system for showing students where they are expected to be... For example, my students have one minute to stop their work, clean their station, and move to the next activity. A simple bell denotes the end of one workstation and the beginning of the next. Oftentimes students move quickly and in an orderly manner, trying to beat the bell. The smoother the transition between stations, the more time there is for instruction to take place.

I did not bring a bell and moved a little more organically throughout the stations not paying attention to the exact time. It would have been better to have a timer with a bell and have the students clean up the station before moving to the next. Furthermore, I brought in balloons for the color station and they became a distraction for the students who completed this station earlier in the lesson. Next time, choosing their favorite color balloon should be completed at the end of the entire lesson as to not distract the learners from other tasks. In sum, while I could improve some of the minor organizational details of small group work, all in all the constructivist methodology and the workstations facilitated students' achievement of the learning goals.

\section{Analysis of Process Observations}

Student motivation and classroom atmosphere. In the program, student motivation level is very high. They understand the tasks, help each other, receive feedback willingly and participate with their best effort. This institution has a relaxed but focused atmosphere, it feels like a $2^{\text {nd }}$ home for the community members. They students are on-task but can move freely and have fun. The students' may move around, sit as they like or even lay down as long as they are engaged in learning. The students and professors exclusively speak in English (particularly the older students and more advanced levels) and the students and the teachers/volunteers have great relationships. 
Resources. The institute is equipped with computers and tablets for the students use but due to the poor internet connection, these are not very useful. They have paper, crayons, markers, scissors, CD players and other materials. While the internet would open their worlds even more, the tables, whiteboards and their own notebooks proved quite sufficient since the methodology is so creative. The students themselves and the motivated staff and volunteers are the programs greatest resource, yet they could improve and find creative ways to integrate more media.

Students language level. The student's language level in different areas and ages in the program is overall very impressive. Even in the basic levels, students understand all the instructions and complete all of the tasks they were requested to complete.

Learners role. As the methodology of this course is student-centered with a backwards course design, the learners are at forefront of the construction and application of the educational processes utilized in this curriculum. The course adjusts to how students learn, their specific needs (even as they change), and their attitudes about education and topics discussed. The curriculum is flexible to the students' interests and necessities as foreign language learners.

Facilitators role. The facilitator holds specific knowledge that he/she can transmit while coconstructing knowledge and experiences with the learners. The facilitators job is to encourage the students' individual and collective process of developing their knowledge of English. The facilitators role is secondary as the learners are primary in defining what knowledge they need to integrate in accordance the backwards course design that this curriculum is based on.

Evaluation. If we observe the chart below, we can understand the value of performance tasks and projects over traditional quizzes and tests as they contribute to "enduring understanding" rather than only being familiar with a feature of the language (Forrest, 2017).

Thus, the classes I observed/participated in focused on evaluation and assessment of learners' progress through simulations of real-life situations, role-plays and a written production of the topics seen in each course. The evaluation in each section adapts depending on the learners needs and growing abilities with the language; however, the program does have certain goals and some formal assessments to see if the students have acquired enough language to move to the next level based on the learning goals of each section.

\section{Product Evaluation}

Product evaluations aim to give interpretations of the attainments of the programs and offer recommendations for further growth for the shareholders of a program. As Tunc (2010, p. 26) explains, they "should determine the extent to which identified needs were met, as well as identify the broad effects of the program. ... However, it should also provide direction for modifying the program to better serve the needs of participants and to become more cost effective." Thus, in this product evaluation, we will look at the needs of the program, how well it accomplished those needs and give recommendations of ways the program can continue to grow to offer hope and opportunities in English for the three communities.

This chart provides organizational needs, the programs accomplishments and the evaluators recommendations for further growth: 


\section{Needs}

- Help students achieve a high competence in English

- Motivate students to continue in school

- Keep children out of sex work and drug trafficking

- Boost self-esteem

- Bring work and educational opportunities

- Create closer family bonds

- Give students responsibilities and discipline

- Nourish the desire to help others

- Heal emotional wounds

- Provide strong role models

- Adapt to special needs and learning styles

- Provide updated and useful materials

\section{Accomplishments}

- The students that complete the entire program are equipped to work in the language and help others learn.

- Many of the students stay in high school and graduate due to the support of this institution, volunteers and staff.

- The opportunities provided here give the students motivation, skills and, thus, options and hope.

- The organization has networking projects with many companies and helps students write C/Vs and apply for jobs. They also help the students acquire the skills needed to find work.

- The program offers English classes for the mothers and having them volunteer with their children as part of an integral learning process

- They must attend classes, stay in school, and pass each level. They have responsibilities to fulfill to stay in the program.

- $\quad$ Each student, as they advance in the program, also volunteers and helps others. They also have program where they help in indigenous communities and people in even more abject poverty than they face.

- Counseling and understanding others' contexts as well as receiving individualized attention and assistance helps them recover from past wounds and traumas.

- Students have many mentors such as their teachers, former graduates, volunteers, psychologists to provide different models from within and outside of the community. The mothers taking time to study and learn also become role-models for their kids.

- The constructivist methodology, stations, small group work with multiple volunteers helps work with students' individual needs and learning styles. They also offer personalized tutoring.

- The computer lab: tablets are great and the collection of material are very nice. The professors use great creativity despite the lack of resources.

\section{Recommendations}

- Create an exit exam to assess the levels and have measurable results of overall level in each area: oral, written, listening, and reading.

- Compare drop-out rates between active students and the general population 
- $\quad$ Keep the building networking connections. Offer workshops on interviewing in English and test-taking. Help them take and prepare for the TOEIC and TOEFL and create a fund so they can take these exams as well as University entrance exams.

- Fathers and male adults could be more involved as well as they are also part of the community and the male students need positive role-models as fathers and partners.

- $\quad$ Offer more mentoring programs.

- Add more diversity of teaching methods in the lessons. The kinesthetic and interpersonal styles are great, but they could have more audio-visual activities.

- Work on finding ways to utilize the tablets and computers more even without internet through downloaded programs. Focus on getting donated textbooks with audio/video material. Create resource packs for each level. Provide more printed copies for the students to study from.

\section{References}

Abou-Sayed, Y. (2011). Using Small Groups and Workstations: From Chaotic to Constructive. Texas Child Care Quarterly. Volume 35. No 3. Retrieved from https://www.childcarequarterly.com/pdf/winter11_smallgroups.pdf

Elias, M. J. (2009). The Four Keys to Helping At-Risk Kids. George Lucas Educational

Escamilla, K., \& Grassi, E. (2010). A Brief Description of Second Language Acquisition.

Foundation. Retrieved from https://www.edutopia.org/strategies-help-at-risk-students

FundaVida. (2020). FundaVida. http://www.fundavida.org

$\begin{array}{lllll}\text { FundaVidaCR (2012). Como Amanecera [Video]. Youtube. } & \end{array}$

https://www.youtube.com/watch?v=HNioHc-s6wl

http://schoolengagement.org/school-engagement-services/at-risk-youth/

https://www.sas.upenn.edu/ haroldfs/pedagog/evaluation/evaluate.html

Kawulich, B. B. (2005). Participant Observation as a Data Collection Method. Qualitative

Language Classroom Observation. (2001). University of Pennsylvania.

Naylor, S. \& Keogh, B. (1999). Constructivism in classroom: Theory into practice. Journal of Professional Development Resource Series, Second Language Acquisition. Bueno Center for Multicultural Education, Colorado.

Science Teacher Education, 10, 93-106.

Serving At-Risk Youth. (2020). National Center for School Engagement.

Social Research, 6 (2), Art. 43, http://nbn-resolving.de/urn:nbn:de:0114-fqs0502430

Tunc, F. (2010). Evaluation of an English Language Teaching Program of a Public University using CIPP Model. [Master's thesis, Graduate School of Social Sciences at Middle East Technical University].

\section{Biographical notes:}

Monica Bradley is an English Professor in the Modern Languages Faculty at the University of Costa Rica. She has a M.Ed in English Education with a Specialty in Program Management and Evaluation from the University of Science and Technology (ULACIT), Costa Rica and a Master's of Arts in Women Studies from San Diego State University, United States. Her areas of studies include critical pedagogy, cultural studies, intercultural communication, feminist theory and literature, English as a Second Language and English for Specific Purposes. 